\title{
Conceptual Design of the 45 T Hybrid Magnet at the Nijmegen High Field Magnet Laboratory
}

\author{
S. A. J. Wiegers, A. den Ouden, J. Rook, J. A. A. J. Perenboom, H. H. J. ten Kate, M. D. Bird,
}

A. Bonito-Oliva, and J. C. Maan

\begin{abstract}
A 45 T Hybrid Magnet System is being developed at the Nijmegen High Field Magnet Laboratory as part of the Nijmegen Center for Advanced Spectroscopy. The 45 T Hybrid Magnet System will be used in combination with far-infra-red light produced by a Free Electron Laser under construction directly adjacent to the High Field Magnet Laboratory. The superconducting outsert magnet will consist of three CICC coils wound on a single coil form, using $\mathrm{Nb}_{3}$ Sn strands. A test program for strand and cable qualification is underway. The CICC will carry $13 \mathrm{kA}$ and the coils will produce $12 \mathrm{~T}$ on axis field in a 600 $\mathrm{mm}$ warm bore. The nominal operating temperature will be 4.5 $\mathrm{K}$ maintained with forced-flow supercritical helium. The insert magnet will produce $33 \mathrm{~T}$ at $40 \mathrm{kA}$ in a $32 \mathrm{~mm}$ bore consuming 20 MW, and will consist of four coils. The insert magnet will be galvanically and mechanically isolated from the outsert magnet. Complete system availability for users is expected in 2014. In this paper we will report on the conceptual design of the $45 \mathrm{~T}$ Hybrid Magnet System.
\end{abstract}

Index Terms-CIC conductor, high field magnets, hybrid magnets, superconducting magnets.

\section{INTRODUCTION}

A new Hybrid Magnet System is being developed at the Nijmegen High Field Magnet Laboratory. The target on axis magnetic field is $45 \mathrm{~T}$, of which $12 \mathrm{~T}$ will be delivered by the superconducting outsert magnet, and $33 \mathrm{~T}$ by the resistive insert magnet.

In the past decade a number of Hybrid Magnet projects in several High Magnetic Field Facilities have been started [1]-[4]. It is generally agreed that the superconducting outsert magnets should be very robust and reliable to be able to operate in conjunction with a resistive insert magnet in user facilities [5]. Therefore, we have adopted the CIC conductor technology to fabricate the coils, and we adhere to the good practices recently

Manuscript received October 19, 2009. First published March 25, 2010; current version published May 28, 2010. This work was supported by the Dutch Organization for Scientific Research.

S. A. J. Wiegers, A. den Ouden, J. Rook, and J. A. A. J. Perenboom are with the Nijmegen High Field Magnet Laboratory and the Institute for Molecules and Materials of the Radboud University, 6525 ED Nijmegen, The Netherlands (e-mail: s.wiegers@ science.ru.nl).

H. H. J. ten Kate is with CERN 1211, Geneva, Switzerland (e-mail: herman. tenkate@cern.ch).

M. D. Bird is with the National High Magnetic Field Laboratory, Tallahassee, FL 32306 USA (e-mail: m.bird@ magnet.edu.usa).

A. Bonito-Oliva is with F4E, 08019 Barcelona, Spain (e-mail: Alessandro. Bonito-Oliva@f4e.europa.eu).

Color versions of one or more of the figures in this paper are available online at http://ieeexplore.ieee.org.

Digital Object Identifier 10.1109/TASC.2010.2043659 developed e.g., in the EDIPO project [6] and the Series-Connected Hybrid projects of the NHMFL [1].

More specifically, we require that the outsert magnet be stable against insert magnet trips, i.e., does not quench, which is a serious complication in a hybrid magnet. We need to consider both the insert and outsert magnets separately during insert trip, but adequate stability can be obtained, as we will show further on in this paper. In case the insert magnet itself develops a failure, we only require that the outsert magnet can be safely discharged, without, but more probably with, a quench.

A distinguishing property of the future Hybrid Magnet is that, due to the exclusive use of "high performance" (non- $\mathrm{Cu} \mathrm{J}_{\mathrm{c}}$ in excess of $2000 \mathrm{~A} / \mathrm{mm}^{2}$ at $12 \mathrm{~T}$ and $\left.4.2 \mathrm{~K}\right) \mathrm{Nb}_{3} \mathrm{Sn}$ superconductor, the outer superconducting coil will be very compact: only $1.2 \mathrm{~m}$ in diameter and about $1 \mathrm{~m}$ in height, the outsert coils together weighing no more than $4000 \mathrm{~kg}$, while the insert magnet's power consumption will be only $20 \mathrm{MW}$. The $12 \mathrm{~T}$ target field for the superconducting outsert magnet has been mainly set by financial constraints: $13 \mathrm{~T}$ requires double the amount of superconductor compared to $12 \mathrm{~T}$.

In the remainder of this paper we will detail the most noteworthy design properties of the future $45 \mathrm{~T}$ Hybrid Magnet System in its conceptual stage.

\section{General Project ApProach}

After we decided to use an all- $\mathrm{Nb}_{3} \mathrm{Sn}$ based CIC conductor, following expert advice, we have investigated several scenarios to obtain a viable design and fabrication path. After ample deliberation on manageability and cost of the total project, we decided to approach the project by forming a small in-house design team that will be using existing well-proven technology on a conservative and as standard as possible superconducting magnet design. Because our Laboratory also has experience with designing and fabrication of resistive magnets (also insert magnets: we have recently completed a $22 \mathrm{~T}$ insert for our $30 \mathrm{~T}$ $50 \mathrm{~mm}$ bore Hybrid magnet) as well as operational experience with hybrid magnets, we should be able to oversee the whole system, notably the interaction between the insert and outsert magnets. For expert advice and specific help not available within our Laboratory we will need to refer to outside sources.

We have deliberately chosen for a moderately performing superconducting outsert magnet ( $12 \mathrm{~T}$, while $\mathrm{Nb}_{3} \mathrm{Sn}$ technology could deliver $>14 \mathrm{~T}$ ), to allow for an adequate operational margin, a standard design and to reduce cost. Inspection of the choices left after choosing CIC conductor, $12 \mathrm{~T}$, operational current between $10 \mathrm{kA}$ and $15 \mathrm{kA}$, three subcoils, and $30 \%$ void, learns that there are only very few: e.g., temperature margin of the conductor, choice of strand, outsert magnet protection, and 
some cryogenic choices. We will describe our considerations on some of these choices in the next paragraph.

\section{Conceptual Design of the Hybrid Magnet System}

\section{A. Strand Properties}

The superconducting strand properties determine to a large extent the conductor properties and dimensions of the coils. Two magnet projects (EDIPO [6], and the Series-Connected Hybrids [1]) have been using "advanced" $\mathrm{Nb}_{3} \mathrm{Sn}$ strands, with non- $\mathrm{Cu} \mathrm{J}_{\mathrm{c}}$ larger than $2200 \mathrm{~A} / \mathrm{mm}^{2}$ at $12 \mathrm{~T}$ and $4.2 \mathrm{~K}$. We have investigated a $0.81 \mathrm{~mm}$ diameter Bruker/EAS PIT strand in a qualifying program, the results of which are reported at this conference in a separate paper [7]. One of the findings therein is that the PIT wire withstands the irreversible $\mathrm{J}_{\mathrm{c}}$-deteriorating tensile strain that often occurs in a CICC in operation up to $+0.1 \%$. This is certainly a property that is very desirable from a stability point of view during the $>10$ years life-time of the magnet. The outsert will be ramped up and down at most once a day or a week, so in our case hysteresis losses will not be very critical to the design. On the contrary, AC losses are important because they determine the warming up rate of the outsert during insert trip, which is one of the system failure modes to be considered.

\section{B. Conductor}

Much effort has been put recently in validating and predicting the performance of CIC conductors. By now a number of predominantly empirical rules have been established, which seem to deliver CICC's with well-defined and non-deteriorating properties [8], [9]. Both EDIPO and the SC-Hybrids use 316LN as jacket material, and we will conservatively do so likewise, despite the appealing advantages of using a conduit material with less thermal contraction (e.g., Ti-alloy based). We choose the usual rectangular conduit shape for the three coils (HF, MF and LF). In combination with a $\sim 30 \%$ void, and twist pitches optimized with TEMLOP [10] we arrive at a configuration which is considered proven technology.

We have decided to develop a CIC conductor with moderate operational current $(<15 \mathrm{kA})$ to reduce cost (power supply, current feedthroughs), but still resulting in a low enough inductance magnet to extract the magnetic energy quickly during quench or soft trip (see Section III-D).

To tune the operational current around $13 \mathrm{kA}$ we need around 100 superconducting strands in the HF conductor leaving about $1.5 \mathrm{~K}-2 \mathrm{~K}$ temperature margin at the windings. We also use $\mathrm{Cu}$ wire in the $\mathrm{HF}$ cable for sufficient $\mathrm{Cu}$ cross section to limit the heat generation during current sharing.

The operation of the insert will be such that above an outsert field of $11 \mathrm{~T}$, the insert magnet will be ramped up to more than $80 \%$ of maximum insert field, to profit from the return field of the insert magnet lowering the peak field on the windings.

The above considerations lead to four cabling stages, $3 \times 3 \times$ $4 \times 4=144$ strands, with twist pitches given in Table I, where also other conductor properties have been listed, e.g., the copper current density $\mathrm{J}_{\mathrm{Cu}}$. The twist pitches have been chosen such as to minimize the $\mathrm{J}_{\mathrm{c}}$ degrading as a result of thermal differential contraction and the cyclic electromagnetic loading. The LF and MF coil will use a smaller size conduit than the HF conductor.
TABLE I

CONDUCTOR PARAMETERS

\begin{tabular}{|c|c|c|c|}
\hline Property & HF Conductor & MF Conductor & LF Conductor \\
\hline \# strands & 144 & \multicolumn{2}{|c|}{108} \\
\hline Cabling pattern & $3 \times 3 \times 4 \times 4$ & \multicolumn{2}{|c|}{$3 \times 3 \times 3 \times 4$} \\
\hline Twist lengths & \multicolumn{3}{|c|}{$84 / 140 / 182 / 222 \mathrm{~mm}$} \\
\hline Jacket material & \multicolumn{3}{|c|}{ Stainless steel $316 \mathrm{LN}$} \\
\hline $\begin{array}{l}\text { Jacket outer } \\
\text { height } \mathrm{x} \text { width }\end{array}$ & $20.1 \times 11.0 \mathrm{~mm}^{2}$ & \multicolumn{2}{|c|}{$17.1 \times 10.6 \mathrm{~mm}^{2}$} \\
\hline Wall Thickness & \multicolumn{3}{|c|}{$2.0 \mathrm{~mm}$} \\
\hline Void fraction & \multicolumn{2}{|c|}{$29 \%$} & $29 \%$ \\
\hline \# SC strand & 96 & 36 & 24 \\
\hline \# Cu strands & 48 & 72 & 84 \\
\hline $\mathrm{J}_{\mathrm{Cu}}$ & $236 \mathrm{~A} / \mathrm{mm}^{2}$ & $259 \mathrm{~A} / \mathrm{mm}^{2}$ & $247 \mathrm{~A} / \mathrm{mm}^{2}$ \\
\hline
\end{tabular}

Although a separate cable test will be necessary for each type, this is still the most cost-effective solution.

In the MF and LF conductor a greater fraction of the superconducting wires will be replaced by $\mathrm{Cu}$ (or possibly Glidcop) to reduce cost. One single conduit size would been chosen for ease of winding, identical hydraulic impedances for equal lengths and less cost, but it also would imply MF and LF cables with so much (soft) $\mathrm{Cu}$ that superconducting strand movement during operation could become an issue.

Although detailed mechanical analysis has to be performed yet, a first analysis indicates that a conduit wall thickness of $2.0 \mathrm{~mm}$ should be sufficient to have some margin against the combination of the helium pressure build up during a quench and the fault forces as the insert develops a fault.

The CICC will be insulated with glass-fiber cloth of $0.3 \mathrm{~mm}$ thickness.

\section{Superconducting Coils}

The superconducting outsert magnet will consist of three coils, HF-MF-LF, wound on top of each other. Mechanically the coils will be integrated, with the outer coils radially supporting the inner ones. No further radial support will be necessary. After winding and heat treatment the coils will be vacuum-impregnated.

The main parameters of the coils are listed in Table II. The operational curent for a $12 \mathrm{~T}$ on axis field is $12630 \mathrm{~A}$, where the coils have about $44 \mathrm{MJ}$ of stored magnetic energy.

\section{Protection of the Outsert Coils}

The conductors of the outsert coils nominally have a $2 \mathrm{~K}$ temperature margin. Barring cases where the conductor is significantly locally degraded, the outsert will not quench easily although this is not impossible. A Quench Detection (QD) system on the basis of a pick-up coil co-wound with the CICC will be used to distinguish resistive voltages appearing upon current sharing from inductive voltages.

If a quench of the outsert magnet is detected by the QD system, the power supply (PS) breakers open, extracting energy 
TABLE II

COIL PARAMETERS

\begin{tabular}{cccc}
\hline \hline Property & HF Coil & MF Coil & LF Coil \\
\hline \# layers & 4 & 2 & 14 \\
$\begin{array}{c}\text { Max field at } \\
\text { windings }\end{array}$ & $12.91 \mathrm{~T}$ & $10.13 \mathrm{~T}$ & $8.51 \mathrm{~T}$ \\
$\begin{array}{c}\text { Temperature } \\
\text { margin }\end{array}$ & $1.9 \mathrm{~K}$ & $1.8 \mathrm{~K}$ & $1.9 \mathrm{~K}$ \\
$\begin{array}{c}\text { Temperature } \\
\text { margin with } \\
\text { insert }\end{array}$ & $2.6 \mathrm{~K}$ & $2.4 \mathrm{~K}$ & $1.8 \mathrm{~K}$ \\
$\begin{array}{c}\text { Radial built } \\
\text { Height }\end{array}$ & $360-406 \mathrm{~mm}$ & $406-429 \mathrm{~mm}$ & $429-586$ \\
\hline \hline
\end{tabular}

from the outsert as fast as possible, limited by the maximum allowable $3 \mathrm{kV}$ voltage difference across the terminals. At the same time an insert trip will be initiated to warm up the outsert windings homogeneously creating a large normal zone.

The time constant of the outsert magnet is about $2.4 \mathrm{~s}$, given its inductance of $0.57 \mathrm{H}$ and limiting the discharge voltage over the terminals during a quench to $3 \mathrm{kV}$. Further study is underway to verify that the magnetic energy can be extracted fast enough and shows that the hot spot temperature can be limited to $150 \mathrm{~K}$.

The interaction of the outsert coils with the insert coils requires special attention: the insert-outsert system acts as a transformer with a strong coupling. One must foresee the occurrence of insert trips where the $20 \mathrm{MW}$ power converter ramps the insert current to zero with a time constant of about $0.3 \mathrm{~s}$. This will induce significant AC losses inside the superconductor, warming it up, and inducing a current surge in the outsert coils of about $1 \mathrm{kA}$. Besides this, but much more rare, also insert trips may occur due to an electromechanical failure inside the insert magnet, giving in addition rise to large fault forces between the insert and outsert coils.

Accordingly, we are planning to implement two decay modes for the outsert magnet.

The first one is a limited outsert decay if the insert magnet trips [5]. The outsert decay is necessary to compensate for the inductive current surge due to the failing insert circuit, and to increase the temperature margin of the outsert. The electrical circuit for this mode is shown in Fig. 1. The (PS) breakers will open, with the dump resistor $R_{o}$ switched in. The outsert decay will be stopped when the insert decay is finished by closing the short-circuiting switch (normally open) about $1.0 \mathrm{~s}$ later. This will let the outsert decay between 1 and $2 \mathrm{kA}$ to remain safely superconducting at a current of around $11 \mathrm{kA}$ after the trip. The PS breakers are then closed, the outsert PS will be adjusted to the actual outsert current, the short-circuit switch can be opened, and from there the PS can take the outsert back up again if desired.

The second one is when an insert trip occurs due to an insert magnet failure. A quench of the outsert coils seems almost unavoidable in this case. The PS breakers will be opened and remain opened until the outsert current has fully decayed. The short-circuiting switch remains open all this time. a) $t=0$ insert trip

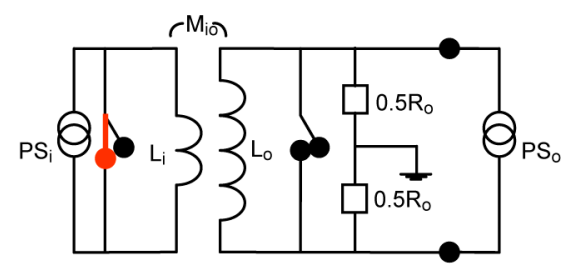

b) $\mathrm{t}=\mathrm{t}_{\mathrm{s}}$ breakers effective (fast low V switching)

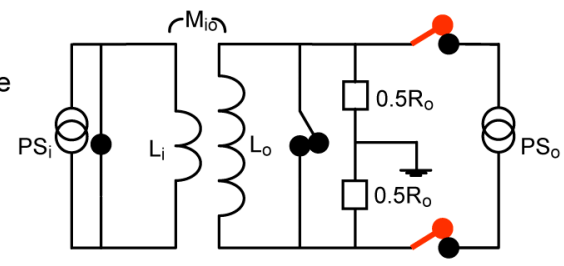

c) $t=t_{s}+t_{s d}$ short effective (slow high $\vee$ switching)

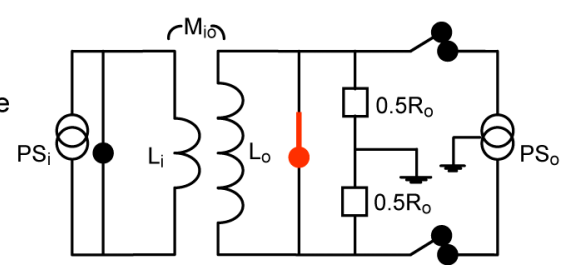

Fig. 1. The superconducting circuit during insert trip is shown. The dump resistor $R_{0}$ is always connected to the magnet. As the outsert power supply breakers open (b) due to an insert trip (a), energy is extracted from the magnet during a time $t_{s d}$. After this time the short-circuit comes in (c).

Also, large axial fault forces (up to $2 \mathrm{MN}$ ) between the insert and outsert coils start to appear, and these need to be contained or avoided. We choose the latter, which requires the insert to move during fault force development whereby the fault forces on the outsert coils are reduced.

The insert magnet will be mounted on a mechanical support that will allow for this vertical movement, but will decelerate the movement such that it will stop after + or $-10 \mathrm{~cm}$ displacement. To facilitate such a displacement the insert cooling water piping will be flexibly mounted using Victaulic couplings, as is also the case for the existing $30 \mathrm{~T}$ Hybrid Magnet.

The mechanical decoupling of the insert magnet from the outsert magnet minimizes the structural requirements for the outsert cryostat, reducing cost and complexity.

\section{E. Cryogenic System}

The coils will be mounted inside a magnet vessel, which both mechanically supports the coils axially and contains supercritical helium to reduce the heat load on the coils. The helium will be partly vented from the coils for this purpose, i.e., the magnet will be a wet magnet. All hydraulic interconnects and electrical joints will be inside the magnet vessel. This has the additional advantage that we need not be concerned with small helium leaks, and the disadvantage that we should treat the magnet vessel as a pressure vessel, nominally at a pressure of 3 bars, which means that some reinforcement will be necessary. The latter can be done in conjunction with the axial containment of the outsert coils, which should not be allowed to move.

The magnet cryostat will have a thermal shield kept at around $40 \mathrm{~K}$ by circulating cold helium gas from a $1600 \mathrm{~W}$ Stirling refrigerator. The Stirling refrigerator will also be used to cool down the system, and keep the magnet below $100 \mathrm{~K}$ when not in operation. 
TABLE III

HYDRAULIC PARAMETERS

\begin{tabular}{cccc}
\hline \hline Property & HF Coil & MF Coil & LF Coil \\
\hline $\begin{array}{c}\text { Pressure drop } \\
\text { per layer }\end{array}$ & $0.97 \mathrm{bar}$ & $0.97 \mathrm{bar}$ & $0.98 \mathrm{bar}$ \\
$\begin{array}{c}\text { Mass flow per } \\
\text { layer }\end{array}$ & $0.79 \mathrm{gr} / \mathrm{s}$ & $0.56 \mathrm{gr} / \mathrm{s}$ & $0.46 \mathrm{gr} / \mathrm{s}$ \\
$\begin{array}{c}\Delta \mathrm{T} \text { due to He } \\
\text { flow }\end{array}$ & $0.31 \mathrm{~K}$ & $0.31 \mathrm{~K}$ & $0.31 \mathrm{~K}$ \\
\hline \hline
\end{tabular}

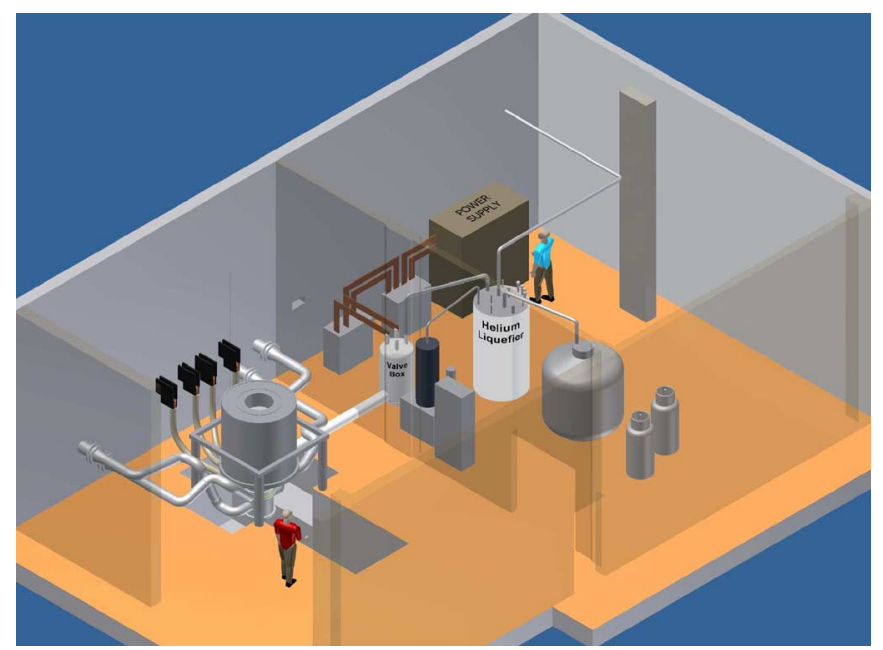

Fig. 2. Artist's impression of the Hybrid Magnet System. The magnet is located in cell 6 , the cryogenics and power supply, the busbar system and the switching gear is set up in the adjacent room.

The outsert coils will be cooled with forced-flow supercritical helium coming from a helium refrigerator via a valve box. The helium flow (see Table III for preliminary values) will be sufficient to compensate for hysteresis and $\mathrm{AC}$ losses during ramping of the outsert and insert coils (ramping time $\sim 0.5 \mathrm{hr}$ ), plus the static heat leaks. In case of a quench the helium flow is dictated by the strong thermal transient in the CICC, and is unaffected by the refrigerator flow. Venting pipes in the hydraulic circuits and on the vessels will be opened to limit the helium pressure build up in these volumes.

\section{F. Resistive Insert Magnet}

The resistive insert magnet will be of the poly-Bitter type, delivering $33 \mathrm{~T}$ at $20 \mathrm{MW}$ in a $32 \mathrm{~mm}$ room temperature bore. The number of coils will be four, allowing utilities access from the bottom of the insert housing.
The insert housing will be designed such that fault forces internal to the insert magnet can be contained within the housing.

\section{G. Hybrid Magnet System Site}

The total system, consisting of magnets, power supply, control and cryogenic system will be installed in cell 6 and in the utility space right next to cell 6 of the High Field Magnet Laboratory, as schematically depicted in Fig. 2.

\section{CONCLUSION}

The R\&D for this project to develop the conductor is underway and is expected to be useful for other high field superconducting magnet projects. The future $45 \mathrm{~T}$ hybrid Magnet will allow many experiments to be performed at the highest DC magnetic fields attainable at present, notably using FIR light from the adjacent Free Electron Laser facility presently under construction.

\section{ACKNOWLEDGMENT}

The authors thank U. Wagner, L. Bottura, T. Salmi, Y. Iwasa, A. Nijhuis, and W. A. J. Wessel for valuable advice and support.

\section{REFERENCES}

[1] M. D. Bird et al., "The NHMFL hybrid magnet projects," IEEE Trans. Appl. Supercond., vol. 19, no. 3, pp. 1612-1616, Jun. 2009.

[2] A. Bourquard et al., "A New Superconducting Coil Outsert for the GHMFL 42 T Hybrid Magnet Project," in IEEE Trans. Appl. Supercond., Jun. 2010, vol. 20, no. 3, 3CO-05.

[3] K. Watanabe et al., "Case study of a $20 \mathrm{~T}-\phi 400 \mathrm{~mm}$ room temperature bore superconducting outsert for a 45 T hybrid magnet," IEEE Trans. Appl. Supercond., vol. 18, pp. 552-555, 2008.

[4] G. Kuang et al., "A 40 T Hybrid Magnet Under Construction in China," in IEEE Trans. Appl. Supercond., Jun. 2010, vol. 20, no. 3, 3CO-03.

[5] A. Bonito-Oliva, "Superconducting high field solenoids for hybrid systems," IEEE Trans. Appl. Supercond., vol. 12, no. 1, pp. 456-461, Mar. 2002.

[6] A. Portone et al., "Design and procurement of the European Dipole (EDIPO) superconducting magnet," IEEE Trans. Appl. Supercond., vol. 18 , no. 2, pp. 499-504, 2008.

[7] A. den Ouden et al., "Nb3Sn Strand Characterisation for the Nijmegen 45 T Hybrid Magnet," in IEEE Trans. Appl. Supercond., Jun. 2010, vol. 20, no. 3, 1GO-01.

[8] A. Vostner et al., "Development of the EFDA dipole high field conductor," IEEE Trans. Appl. Supercond., vol. 18, no. 2, pp. 544-547, Jun. 2008.

[9] I. R. Dixon et al., "Current sharing and AC loss measurements of a cable-in-conduit conductor with Nb3Sn strands for the high field section of the series-connected hybrid outsert coil," IEEE Trans. Appl. Supercond., vol. 19, no. 3, pp. 2466-2469, Jun. 2009.

[10] A. Nijhuis and Y. Ilyin, "Transverse load optimization in Nb3Sn CICC design; influence of cabling, void fraction and strand stiffness," Supercond. Sc. Technol., vol. 19, pp. 945-962, 2006. 